\title{
Cross-Border Exchange of Information and Cooperation Between Insurance Supervisors
}

\author{
Peter Braumüller* \\ Financial Market Authority (FMA), Praterstraße 23, Vienna A-1020, Austria. \\ E-mail: peter.braumueller@fma.gv.at
}

With the insurance business becoming increasingly international, supervisory authorities need to increase cross-border cooperation with other supervisory authorities if they want to be able to achieve their supervisory objectives. Today, effective protection of domestic policyholders and the maintenance of a sound and stable domestic insurance market increasingly depend on the effective analysis of the risks arising from cross-border activities and the overall assessment of the insurer's or group's risk profile.

The Geneva Papers (2007) 32, 301-318. doi:10.1057/palgrave.gpp.2510138

Keywords: regulation and supervision; cross-border cooperation

\section{Introduction}

Over recent years, insurance business has become increasingly international. On the one hand, business strategies of many insurance companies and groups include the expansion of activities into other markets, through branches, subsidiaries, joint ventures, cooperation agreements with local insurers or direct cross-border selling of their insurance products. On the other hand, political changes, trade liberalisation, privatisation, the establishment of integrated market structures, technological developments, increased need for underwriting capacity for large risks and demand for reinsurance capacity outside jurisdictions have created new opportunities. As a result of those developments, we can find today a significant number of internationally active insurers as well as insurance groups and financial conglomerates doing business in many different markets.

In order to effectively achieve the main supervisory objectives in that reshaped environment, supervisory cooperation is a key element. Supervision of the domestic business of insurers by the local supervisor can only be the starting point. In addition, the internationally active insurance undertakings have to provide the supervisor information on all their activities abroad and cross-border relations. The information received from the supervised company has to be examined and analysed by the competent supervisor and it has to be supplemented by information from other supervisors on the cross-border activities of the particular insurer or group and about the respective markets and their legal, economic and financial frameworks, and in particular on the risks involved. Today, effective protection of domestic policyholders

\footnotetext{
${ }^{*}$ The views expressed in this paper are only those of the author.
} 
and the maintenance of a sound and stable domestic insurance market increasingly depend on the effective analysis of the risks arising from cross-border activities and the overall assessment of the insurer's or group's risk profile. It may well be the case that the really crucial risks for an insurance undertaking result from its foreign activities or cross-border relations. Consequently, it is no longer possible to exclusively rely on the concept of solo supervision of legal entities within their jurisdiction. ${ }^{1}$

The issue of cross-border information exchange and cooperation has become an important and even crucial issue for insurance supervisors over recent years. The steadily growing relevance of insurance groups that include entities in different jurisdictions as well as the increase of other cross-border relations ${ }^{2}$ require information exchange and cooperation between the relevant supervisory authorities. In the case of financial conglomerates, the need for cooperation also extends to the cooperation between insurance, banking and securities supervisors. ${ }^{3}$ At present, several projects are on the way to further improve cross-border cooperation. ${ }^{4}$

In the following, the areas in which cross-border cooperation is particularly crucial shall be highlighted. Then, the legal framework for information exchange will be examined as concerns possible barriers for effective international cooperation. A further section will deal with the activities on a global and European level for improving cross-border cooperation between insurance supervisory authorities, followed by conclusions on the present situation and possible future developments.

\section{The main areas for cross-border cooperation between insurance supervisors}

In the following, the need for information exchange and cooperation between supervisors and the way this is organised in practice shall be analysed for the main areas of insurance supervision. Besides cooperation standards and arrangements on specific topics, both international standards and European legislation set up a general requirement for information exchange and cooperation. According to the IAIS (International Association of Insurance Supervisors) Insurance Core Principles, the insurance supervisory authorities cooperate and share information with other relevant supervisors subject to confidentiality requirements. ${ }^{5}$

In the EU, the insurance directives also contain some general rules on supervisory cooperation. It is stipulated that the insurance supervisory authorities shall collaborate closely for the purpose of facilitating supervision of direct insurance ${ }^{6}$

\footnotetext{
${ }^{1}$ IAIS (2002, Preamble, para 2).

${ }^{2}$ Like reinsurance with foreign reinsurers, use of distribution channels in other countries or the outsourcing of activities to entities abroad.

${ }^{3}$ The cooperation between supervisors of different financial sectors cross-border requires effective cooperation between the different supervisors within a jurisdiction. Integrated supervisors certainly facilitate such cooperation, both on a national and international basis.

${ }^{4}$ For example, the IAIS project on the establishment of a Multilateral Memorandum of Understanding (MMoU) or - in the EU - the work on the revision of the Siena Protocol on multilateral cooperation among EU insurance supervisory authorities.

${ }^{5}$ IAIS (2003, ICP 5).

${ }^{6}$ EU Council of Ministers (1988, Art. 28; 2002a, Art. 62).
} 
and reinsurance ${ }^{7}$ and that they shall furnish each other with the documents and information necessary for the supervisory purposes. ${ }^{8}$ As concerns the cooperation in the field of supervision of financial conglomerates, EU legislation calls for close cooperation between the supervisors of all regulated entities in a financial conglomerate, including the authority responsible for supervision of the financial conglomerate itself. This cooperation also pertains to cross-sector cooperation without prejudice to the respective responsibilities of supervisors according to sectoral rules. ${ }^{9}$

\section{Information on insurance supervision systems}

In order to allow effective cooperation between supervisors on specific matters, it is essential to make available information on the structure and functioning of insurance supervision in the different jurisdictions including the main elements of the regulatory framework and supervisory practice. A single piece of information received from a foreign supervisor might not be adequately assessed and could therefore not create any value added or even be misleading if one is not aware of the main elements of the regulatory and supervisory system where this information comes from. ${ }^{10}$

Already in its early stages, the IAIS has identified a need for providing its members basic information on insurance supervision systems in the different jurisdictions. Since information on the regulatory and supervisory framework is very comprehensive and sometimes complex, the IAIS has developed a tool to allow better and easier access to and use of this information. In 2001, an Insurance Laws Database was established. This database covers all the important areas of insurance supervision and provides basic information on the supervision systems of IAIS member jurisdictions including on the regulatory structure and supervisory practice. As an "information market" it should bridge the gap between rather concrete requests for information on the one hand and the huge volume of relevant information available for each single jurisdiction on the other hand. As a supplement to the IAIS Insurance Laws Database, international standards recommend to make available information on insurance supervision legislation on the supervisor's website. ${ }^{11}$

\section{Authorisation}

According to international standards, a licence is required for the carrying on of insurance business. ${ }^{12}$ Since the licensing procedure is a fitting opportunity to start

${ }^{7}$ EU Council of Ministers (2005, Art. 54).

${ }^{8}$ EU Council of Ministers (1973, Art. 9 para 2; 2002a, Art. 13; 2005, Art. 17).

${ }^{9}$ EU Council of Ministers (2002b, Art. 12).

${ }^{10}$ For example, if a supervisor receives the information that the proper calculation of technical provisions has been audited by an actuary it is essential to have information on the definition and calculation methods of technical provisions, the underlying actuarial assumptions and the type of the actuary system in the other jurisdiction.

${ }^{11}$ According to para 20 and 21 of the IAIS (2004), it is recommended that insurance supervisors should make available information on the relevant legislation in their jurisdiction on their website.

${ }^{12}$ IAIS (2003, ICP 6). 
cross-border collaboration with other insurance supervisors, international standards and European legislation stipulate a consultation between supervisors where an insurance company would like to start a business in another jurisdiction through a branch or a subsidiary. ${ }^{13}$

In general, there are two standard cases where information exchange and collaboration should commence between insurance supervisory authorities at the occasion of the licensing procedure.

Firstly, cooperation is of course essential when a foreign insurance company asks for authorisation in another jurisdiction. The host supervisor ${ }^{14}$ should contact the home supervisor ${ }^{15}$ and obtain all relevant information and particularly be informed about any possible obstacles for issuing a licence. Although most information will be required from the applicant directly, verification through the supervisor of the head office is essential. The type of information that should be exchanged includes the scope of the licence of the company. ${ }^{16}$ Although it seems rather easy to check the scope of a licence, it should be noted that the definition of insurance and insurance classes varies between jurisdictions and therefore it is essential to examine the precise scope of the authorisation. Another important issue is the fitness and propriety of the managers and directors of the company. Generally, the branch will be managed by a representative or a board, but since the branch is part of the overall company, capability of the head office's management is crucial. Furthermore, the supervisor of the head office should provide information on shareholders and reinsurance arrangements. Information on reinsurance arrangements of the company is important since frequently branch business is not reinsured separately but included in the insurance company's overall reinsurance programme.

Secondly, supervisory cooperation is also relevant where a domestic company is going to be authorised and an insurance company domiciled in another jurisdiction is the parent company of the applicant or holds a significant participation in it, or where the applicant and an insurance undertaking in another jurisdiction have the same parent or significant owner. ${ }^{17}$ The supervisor of the parent company ${ }^{18}$ is in a position to submit information on the present status of the parent company, similar to the information mentioned in the context of branch business. Again, information exchange on reinsurance is important especially when the subsidiary is to be mainly or fully covered by a group reinsurance programme. In that case, information on this group programme is essential in order to properly assess the underwriting risk management of the subsidiary by its competent insurance supervisory authority. Last

13 Ibid., ICP 6, essential criteria b and d.

${ }^{14}$ That is, the insurance supervisory authority in the jurisdiction for which the company applies for an authorisation.

${ }^{15}$ That is, the supervisory authority of the insurance company which applies for the licence.

${ }^{16}$ As a rule, an insurance company must not carry on activities beyond its licence, neither in its own jurisdiction nor in any other country.

${ }^{17}$ According to international standards, a significant owner is defined as a natural or legal person that directly or indirectly, alone or with an associate, exercises control over the insurer (IAIS (2003, ICP 7, explanatory note, para 7.1)).

18 In the following, the term "parent company" should include cases where this company holds a significant participation. 
but not least it is important to exchange information between supervisors on the managers and board members because persons of the parent company are taking decisions that might affect other companies in the group and they might also hold positions in the newly established insurance subsidiary. In 2002, the EU introduced the requirement of consultation between supervisors prior to the granting of an authorisation. This cooperation also includes cross-sector collaboration, and it has to take place if the applicant is a subsidiary of an EU insurance company, credit institution or investment firm or subsidiary of the parent company of an EU insurance company, credit institution or investment firm or controlled by the same persons who control an EU insurance company, credit institution or investment firm.

Cooperation becomes more difficult where the parent undertaking is a credit institution or securities firm or even an unregulated entity. Where no arrangements exist on the direct cross-border cooperation between supervisors responsible for different financial services sectors, an information exchange might be established through the insurance supervisory authority in the jurisdiction where the parent company is located. In case the supervisory authority of the parent company is an integrated supervisor this should allow direct and easy flow of information.

The authority responsible for the supervision of the branch or the subsidiary may refuse the licence or put conditions upon the authorisation in case the supervisor of the head office or the parent company has major concerns regarding the setting up of the branch or subsidiary.

Finally, as a necessary supplement to the cooperation during an authorisation procedure, it is essential that supervisors also collaborate as concerns unauthorised business and illegal activities. If an authorisation was withdrawn or lapsed or where measures relevant to further business activities were imposed, ${ }^{19}$ the relevant insurance supervisor should inform the insurance supervisory authorities of all jurisdictions in which the company is active about those measures or circumstances. The same goes for warnings against illegal or fraudulent providers of insurance services with a crossborder impact.

\section{Ongoing supervision}

The cooperation between supervisors during the licensing process would not add much to an effective supervision if it were not continued after the licence was issued.

Changes in licensing criteria of the head office or parent company should be reported immediately by the home supervisor in order to allow the supervisor of the branch or subsidiary to take appropriate action on time. Furthermore, all major changes in the company's legal or financial position should be communicated to supervisors of jurisdictions where a regulated entity holding a significant participation is located or where another regulated company belonging to the same group is situated. Changes in control of an insurance company may require coordination with supervisors in other jurisdictions. ${ }^{20}$

\footnotetext{
${ }^{19}$ Like the prohibition or restriction of new business.

${ }^{20}$ IAIS (2003, ICP 8, essential criterion d).
} 
306

The cooperation on a permanent and active basis is becoming increasingly important since the composition of boards and shareholders as well as the relations between the supervised insurer and other regulated or unregulated companies have become much more dynamic in recent years. That means that the parameters that were examined by the insurance supervisory authority during the licensing process might already be very different only a short time after the licence was issued.

An area that requires specific attention by supervisors is the supervision of insurance activities through electronic means and in particular through the Internet. Since Internet sites can be accessed globally and this type of insurance business very easily crosses national borders and is a very dynamic way of doing business, more intensive cooperation between insurance supervisors is required. ${ }^{21}$ The use of the Internet for the marketing of insurance products might also open up new opportunities for fraudulent operators. An additional difficulty arising from Internet business is that it might in some cases not be easy to identify home and host supervisors and therefore responsibilities could possibly remain unclear. Finally, however, it should also be mentioned that the Internet also allows more rapid and efficient information exchange between supervisors at least as concerns non-sensitive information.

Another important issue of ongoing supervision is the exchange of financial and statistical information. Over the last few years, the financial and statistical information available has considerably increased and the insurance supervisors' websites have made access thereto much easier and quicker. The objective of exchange of financial data is two-fold. On the one hand, information on the financial status of a branch or subsidiary of an insurance undertaking in another country might provide the opportunity for the supervisor to check and verify the information received from the parent company or head office. At least equally important is the overview of other insurance markets. Only a good understanding of the markets in which an insurance undertaking or insurance group is active allows a proper and comprehensive analysis of the overall financial status of the company and the group.

Based on the principle of home country control in the internal insurance market, the EU concept foresees that only the home supervisor is responsible for financial supervision of an insurance company domiciled in its territory. This also applies if the insurance company is the subsidiary of an insurer located in another EU member state, but in that case the subsidiary might - in addition - be included in group supervision by the lead supervisor. ${ }^{22}$ For activities through branches or provision of services, EU legislation provides for an exchange of some basic information in aggregate form in order to allow the host supervisor to get an idea of the total volume of business transacted in its jurisdiction by insurers from other EU member states. ${ }^{23}$

According to international standards, the insurance supervisors shall carry out onsite inspections to examine the business of an insurer and its compliance with

\footnotetext{
${ }^{21}$ IAIS (2004, Principle 3 and paras 18 and 19).

${ }^{22}$ The tasks and responsibilities of the lead supervisor are defined in European Council of Ministers (1998).

${ }^{23}$ EU Council of Ministers (1992, Art. 44; 2002a, Art. 49).
} 
legislation and supervisory requirements. ${ }^{24}$ In the EU, specific rules exist on the cooperation in the context of on-site inspections. It is the right and obligation of the home supervisor to carry out on-site inspections of branches of a supervised insurance undertaking in other EU member states, and the host supervisor may join the inspection. ${ }^{25}$ Similarly, EU supervisors also conduct joint on-site inspections of insurance companies that are part of an insurance group.

In the EU single market where the licence is valid for the whole territory of the EU it is also very important that measures taken by the home supervisor become effective in the other jurisdictions as well. Therefore, the EC Directives stipulate cooperation as regards certain measures like the safeguarding of the policyholders' interests after the withdrawal of a licence or the blocking of assets. ${ }^{26}$

\section{Cross-border operations through branches and provision of services}

On an ongoing basis, the supervisor of the branch should have all necessary legal and financial information on the company's business and overall financial position since the branch is to a large extent depending on the head office and since legally speaking the head office and the branch are one and the same legal entity. ${ }^{27}$ A situation might easily occur where the financial position of the branch - based on its financial and supervisory reporting - still looks fine whereas the insurance company as a whole is already in financial difficulties. This might rather sooner than later impact on the branch and thus endanger the interests of the local policyholders. Information on problems of the head office might allow the host supervisory authority to take appropriate measures in its own jurisdiction and to ring-fence the branch business on time, for example, through blocking assets or other appropriate measures. Obviously, a conflict of interest could occur between the home supervisor's interest to protect the policyholders in the head office's jurisdiction while the host supervisor has the duty to safeguard the branch policyholders' interests.

According to international standards, ${ }^{28}$ the home supervisor shall inform the relevant host supervisors of any material changes in supervision that may have a significant impact on the operations of branches operating in their jurisdictions. In addition, the home supervisor should inform the host supervisor in advance of taking any action that will affect the branch in the host supervisor's jurisdiction, if that is possible. Vice versa, the host supervisor should inform in advance of taking any action that will affect the headquarters in the home supervisor's jurisdiction. ${ }^{29}$

In general, due to international standards the establishment of a branch of an insurance undertaking in another jurisdiction will require a licence, and due to existing legal restrictions cross-border activities through direct provision of services into another jurisdiction is not common. However, the EU single insurance market allows

${ }^{24}$ IAIS (2003, ICP 13).

${ }^{25}$ EU Council of Ministers (1973, Art. 14; 2002a, Art. 11).

${ }^{26}$ EU Council of Ministers (1973, Art. 20 and 22; 2002a Art. 37 and 39).

${ }^{27}$ Despite the fact that the branch is dealt with like a separate entity in specific areas like accounting.

${ }^{28}$ IAIS (2003, ICP 5, essential criteria $h$ and i).

${ }^{29}$ Ibid., ICP 5, essential criterion j. 
activities of any insurer licensed in one EU member state in any other EU member state based on the home country authorisation, just by notification of its intention to the home supervisor and by fulfilling the criteria of the Directives. As already mentioned, the exchange of basic aggregate information is foreseen in EU legislation. However, no detailed financial data per company is exchanged because of the clear allocation of all financial supervision powers to the home supervisor.

If an EU insurance undertaking wants to start business in another EU member state, notification of its intention to its home supervisor is required. The insurer has to submit information to the home supervisor as defined in the Directives. In case of opening an agency or branch, this information includes the address of the branch in the relevant member state, a scheme of operations and the name of the authorised agent of the branch as well as some additional information if motor TPL insurance is concerned. If the insurance undertaking does not want to establish a branch but carry out business by free provision of services it only has to provide information on the type of risks it wants to cover and the name of the EU member state concerned as well as some additional information if motor TPL insurance is concerned. If the solvency position of the insurer meets the EU requirements the home supervisor submits the relevant information to the respective host supervisor. If the mentioned procedure is finalised the insurer may take up business activities in the other EU member state.

The host supervisor has no possibility to prevent an EU insurer domiciled in another EU member state from starting activities in its territory, either through establishment of a branch or agency or through direct cross-border provision of services. However, the host supervisor has a role as concerns the compliance of the insurer's activities with host country legislation. If an insurer located in another EU member state is not complying with the legal provisions applying to it in the host jurisdiction, the host supervisor may contact the insurer directly, ask for relevant documents and carry out on-site inspections. As far as supervisory measures are concerned, the home-country principle applies, which means that the host supervisor has to ask the home supervisor to take appropriate action. Only if the home supervisor does not take any appropriate measures or if those measures prove inadequate or if the insurer - despite those measures - continues to infringe the legal provisions in the host jurisdiction, the host supervisor may take measures on its own and finally prevent the insurer from continuing business activities in its territory. ${ }^{30}$

\section{Insurance groups and financial conglomerates}

Cross-border activities of an insurance company may not only be carried out by the insurance undertaking itself but through subsidiaries or other companies related to the parent insurance company. Although the insurance company and its subsidiaries are separate legal entities there might be considerable legal or financial connections between them.

The type of relations between the companies of the group might differ from case to case. However, what is important in a supervisory context is that in an insurance

\footnotetext{
${ }^{30}$ EU Council of Ministers (1992, Art. 40; 2002a, Art. 46; 2005, Art. 47).
} 
group or financial conglomerate, risks might more easily pass from one company of the group to another because of the economic links between the group members. Furthermore, group structures can also be used for multiple gearing of capital, which means that capital is used more than once in different companies of the group. Therefore it might be the case that all insurance companies of the group meet the solvency requirements on a solo basis, but on a consolidated basis the total available capital/solvency margin does not suffice to cover the aggregate group capital requirement. A second issue is that of intra-group transactions that could have considerable influence on the different insurance companies of the group, in particular if those are not arm's length transactions.

Another crucial issue is the understanding of complex and rapidly changing group and conglomerate structures in order to be able to carry out effective insurance supervision. The mapping of groups and conglomerates seems an easy task in theory, but may turn out to be a rather complex exercise in practice. Since shareholder control has to be comprehensive it has to include all different layers of direct and indirect shareholders that have to be assessed. Since insurance group and conglomerate structures become more complex and fast changing, additional challenges for the supervisors arise. Consequently, the only chance to maintain an appropriate level of supervision is close cooperation between insurance supervisors of different jurisdictions and different financial services sectors.

However, also cross-border groups that do not meet the national or international definitions of financial conglomerates ${ }^{31}$ might call for supervisory cooperation. Those cases include the outsourcing of significant activities abroad and the dependence on specific distribution channels in other jurisdictions.

According to international standards, ${ }^{32}$ the group supervisor shall inform the other relevant supervisors of any material changes in supervision that may have a significant impact on the operations of subsidiaries operating in their jurisdictions. In addition, the group supervisor should inform the other relevant supervisors in advance of taking any action that will affect the subsidiary, if that is possible. Vice versa, the supervisor of the subsidiary should inform in advance of taking any action that will affect the parent company. ${ }^{33}$

\section{Reinsurance activities}

Traditionally, reinsurance activities have been an international business. In many jurisdictions, there is not enough coinsurance and reinsurance capacity to allow domestic direct insurers to satisfy the demand for coverage by local policyholders, in particular as concerns large risks and industrial lines of business.

For a direct insurance undertaking, outward reinsurance provides the opportunity to underwrite risks which exceed its own risk limits. Through transferring part of its risks to a reinsurer, the ceding company may be permitted to take credit for

\footnotetext{
${ }^{31}$ For the EU, a definition is included in EU Council of Ministers (2002b, Art. 3).

${ }^{32}$ IAIS (2003, ICP 5, essential criteria $\mathrm{h}$ and $\mathrm{i}$ ).

${ }^{33}$ Ibid., ICP 5, essential criterion j.
} 
310

reinsurance ceded in the balance sheet, which might reduce the technical provisions to be covered by admissible assets ${ }^{34}$ and also improve its capital position. ${ }^{35}$

While - economically speaking - part of the risk is transferred to the reinsurer the direct insurer remains obliged to fulfil its commitments vis-à-vis the policyholder to the full extent. Therefore, the ceding company is depending on the legal and financial ability and willingness of the reinsurance company to meet its obligations when they fall due. Finally, it should not be forgotten that there might be a significant time lag between the conclusion of the reinsurance contract and the actual payment of a claim covered by the reinsurance contract. Over this long period of time the financial position of the reinsurer might change considerably.

Taking into account the importance of reinsurance in general and the impact of reinsurance on the fulfilment of obligations of the ceding company vis-à-vis its policyholders, it is important that the direct insurer carefully examines all relevant legal aspects ${ }^{36}$ and financial criteria ${ }^{37}$ of the reinsurance company before it enters into a contract $^{38}$ and that it takes all necessary measures to avoid inappropriate reinsurance arrangements ${ }^{39}$ or programmes or excessive concentration or counterparty risks. This assessment has to be followed by an ongoing monitoring of all reinsurance companies of the company concerned in order to be able to take measures in time. ${ }^{40} \mathrm{In}$ order to allow the insurance supervisor of the ceding company to effectively assess the appropriateness of an insurance company's reinsurance programme, information exchange with the supervisors of the accepting reinsurance companies is essential. ${ }^{41}$

Another case of necessary information exchange among insurance supervisors might come up where the supervisory authority of the accepting company needs further information on the business. This is of course important where pure reinsurers are supervised or a direct insurer for which reinsurance accepted forms a substantial part of the business. In those cases information received from the supervisors of the ceding companies could be essential to reach a comprehensive assessment of the accepting company's risk profile. One should bear in mind that categorisation of insurance business, naming of risks and contract law and treaty clauses vary considerably between jurisdictions.

${ }^{34}$ If coverage on a net basis is permitted.

35 According to EC Directives, outward reinsurance might reduce the required solvency margin, for example, in non-life insurance up to 50 per cent.

${ }^{36}$ For example, the scope of the licence or registration of the reinsurance company or whether there are any restrictions on cross-border payments.

${ }^{37}$ For example, published accounts and business reports, ratings.

${ }^{38}$ OECD Recommendation of the Council on the Assessment of Reinsurance Companies.

39 According to international standards, the reinsurance arrangements have to be part of the licensing criteria (IAIS (2003, ICP 6, essential criterion g)) and are subject to an ongoing review by the supervisor in order to check that they are adequate and claims on reinsurers are recoverable (IAIS (2003, ICP 19, essential criterion e)).

${ }^{40}$ For example, reduce credit for certain reinsurers in the balance sheet.

${ }^{41}$ In order to provide support to insurance supervisors in this area the IAIS has introduced a Reinsurers Database which provides essential information on pure reinsurance companies and direct insurers with a significant share of reinsurance business. One of the main objectives of this database is to allow the supervisor of the ceding company to identify a reinsurance company and the responsible supervisor who can be addressed for more detailed information. 


\section{Portfolio transfer}

Based on the general principles of private law in most jurisdictions the transfer of insurance contracts would require the consent of the contracting parties, that is, the insurance company and the policyholder. In practice, that would mean that the transfer of a whole portfolio from one insurer to another would be impossible in most cases. At the same time, the instrument of portfolio transfers serves as a very useful supervisory tool in practice, in particular in cases of group restructuring or when it is necessary to shift the policies from a problem company to a sound insurer. Therefore, the possibility of such transfers has been incorporated in the local insurance rules of many jurisdictions around the globe.

In general, the procedure of portfolio transfer ${ }^{42}$ is governed by the insurance supervisor of the transferring company. Supervisory cooperation becomes an issue when either the receiving company is located in another jurisdiction or when risks or policyholders in other countries are concerned. Outside the EU, cooperation will be deemed necessary in cases of a portfolio transfer to a branch office of a foreign insurer or if either the transferring or the receiving company have foreign shareholders, in particular regulated entities. The cooperation will mainly pertain to the financial assessment of the insurers involved both before and after the transfer and to the question whether the suitability of the management and shareholders is still valid especially when large portfolios or portfolios with specific risks are to be transferred.

In the EU, the single market concept requires a more sophisticated approach since the EU-wide validity of an insurance licence means that portfolio transfers can be carried out cross-border and policyholders or risks from many different other EU jurisdictions may be affected. According to EU legislation, the supervisor responsible for the approval of the transfer has to involve the supervisor of the accepting insurer, the supervisors of all jurisdictions in which risks or policyholders are located and, if the portfolio of a branch office is concerned, also the supervisor of the branch office. ${ }^{43}$

Recent portfolio transfers in the EU have demonstrated that even in rather simple cases, a considerable number of insurance supervisors and other competent authorities from different countries have to be involved in the procedure. Practical problems arise mainly from the fact that in some jurisdictions it is not the insurance supervisor who is responsible for the approval of a portfolio transfer but another authority or the courts. This makes it sometimes very difficult for the supervisory authority that governs the procedure to decide within an appropriate timeframe. ${ }^{44}$

\section{Outsourcing}

In recent years, outsourcing has become a major concern to insurance supervisors. In this context, outsourcing shall be understood as a significant transfer of essential

\footnotetext{
${ }^{42}$ Which will in most cases be an approval procedure (IAIS (2003, ICP 8, essential criterion j)).

${ }^{43}$ EU Council of Ministers (1973, Art. 28a; 1992, Art. 12; 2002a, Art. 14 and 53).

${ }^{44}$ In many jurisdictions, there are deadlines which have to be met in order to allow for a restructuring to be made on the basis of the last balance sheet date.
} 
business functions from an insurance undertaking to another institution. The main problem for supervision arising from such outsourcing activities is to maintain the same level of effective oversight and supervision of the whole company as before, in particular when those functions are transferred to foreign or unregulated entities.

If business functions are outsourced to a regulated financial entity ${ }^{45}$ in another jurisdiction, cooperation with the local supervisor might help to receive relevant data or to verify information received by the supervised insurance company on its outsourced activities. If legally possible in the respective jurisdiction, the supervisor there might also carry out an on-site inspection on behalf of or together with the supervisor of the insurance company.

According to international standards, the provision of information on contracts with affiliates and outsourcing is a licensing criterion. ${ }^{46}$ Effective on-site supervision of an insurer's activities has to address functions outsourced to another entity and information outside the company. ${ }^{47}$ This can be implemented through specific powers of the supervisor in legislation or through explicit provisions in the outsourcing contract that grant the supervisor an access to information held outside the insurance undertaking and the right to carry out on-site inspections in the entity concerned. However, in both cases it might prove difficult to exercise those powers in practice if the outsourcing is done cross-border and the other jurisdiction's legal and constitutional framework does not foresee formal action to be taken by a foreign authority in that jurisdiction.

The situation is even more difficult if the company to which activities are outsourced is an unregulated entity. In such a case, the insurance supervisor in the jurisdiction concerned does not - in general ${ }^{48}$ - dispose of any power to ask for or verify information as concerns this entity nor would there be a possibility to carry out on-site inspections.

\section{Illegal and fraudulent activities}

Money laundering and financing of terrorism have increasingly come to the attention not only of politicians but also of insurance supervisors. To combat money laundering and the financing of terrorism requires increased cooperation among supervisors ${ }^{49}$ since it is quite likely that persons involved in fraudulent activities intend to escape supervisory control in using complex group structures and cross-border connections to disguise their real activities.

The IAIS has recently strengthened its standards on fraud and AML/CFT. The competence to deal with fraud and AML/CFT issues is regulated differently between jurisdictions. Therefore, cross-border cooperation between supervisors can only be successful if the cooperation between the insurance supervisor and the other

\footnotetext{
${ }^{45}$ For example, insurance company, credit institution, investment firm.

${ }^{46}$ IAIS (2003, ICP 6, essential criterion b).

${ }^{47}$ IAIS (2003, ICP 13, explanatory note, par 13.7).

${ }^{48}$ In the EU, there are some exceptions to this rule if the unregulated entity is part of an insurance group.

${ }^{49}$ IAIS (2003, ICP 5, Explanatory note, point 5.2)
} 
responsible institutions works well in the jurisdiction. This pertains to appropriate communication with domestic enforcement authorities in the mentioned areas. ${ }^{50}$

Another important area of cooperation is unauthorised and unlawful activities. In order to effectively protect the interests of potential policyholders, it is crucial to stop illegal activities as quickly as possible and to make the prohibition effective cross-border. Insurance supervisors should inform others - and at least the supervisors in those jurisdictions where the respective company is doing business - of the lapse or withdrawal of a licence as well as of any cases of unlawful activities carried out by companies domiciled in their jurisdictions or working from their territories. In order to make the collaboration in the context of illegal activities most effective, both the home and host supervisor should be equipped with a range of appropriate tools. Therefore it should be possible for the supervisor in the country where the company concerned is located to impose a stop to illegal business activities not only in the domestic market but also for such activities abroad. All supervisors should have appropriate tools to effectively stop illegal business activities in their territory and to warn the general public, for example, through announcements on the supervisor's website.

\section{Legal issues and other preconditions for an effective cross-border cooperation}

\section{General considerations}

The main objectives of insurance supervision are the protection of policyholders' interests and the maintenance of safe, fair, stable and efficient insurance markets. ${ }^{51}$

Policyholders may reasonably expect a comparable level of protection of their interests vis-à-vis all insurance companies under the supervision of the local supervisor $^{52}$ independently of whether the insurance company's risks are purely domestic risks or whether the insurer also acquires risks from any type of cross-border activities. Therefore, the insurance supervisory authority has to take due account of all those cross-border relations and activities of the insurance undertaking and assess the risks that may arise from those activities. In case of cross-border issues, cooperation with the supervisors in other jurisdictions is essential for allowing effective discharge of those core supervisory functions.

An insurance supervisory authority shall have the statutory power or legal authority to share relevant supervisory information with the supervisors of insurance companies, credit institutions and investment firms. ${ }^{53}$

${ }^{50}$ Ibid., ICP 27, essential criterion a, and ICP28, essential criterion c.

51 Ibid., ICP 2, essential criterion b.

${ }^{52}$ The situation is different if the policyholder on his/her own initiative chooses to sign a contract with a foreign insurance company that is not supervised by the insurance supervisory authority of the policyholder's country of residence.

${ }^{53}$ IAIS (2002, 2.1, para 6). 


\section{Legal problems of cross-border cooperation}

The main problems concerning information exchange and cooperation among insurance supervisors on a cross-border basis refer to the differences in national legislation. First of all, there is a wide range of laws and regulations relevant to this topic. The range of such pieces of legislation includes constitutional provisions, acts governing civil servants, regulations on professional secrecy, freedom-of-information acts, data protection rules, the insurance law and other financial services legislation, ${ }^{54}$ special rules on the establishment and procedures of the supervisory authority, and other pieces of legislation. ${ }^{55}$

Based on the respective traditions, two completely different systems can be found. One is the principle of freedom of information, which in principle allows access by the public to records kept by the insurance supervisor and such access may only be denied under specific circumstances. The other approach is the principle of confidentiality where information held by the insurance supervisor is in general confidential and might only be disclosed under specific circumstances. ${ }^{56}$ In between many types of mixed approaches can be found.

As concerns the legal possibilities to exchange information with foreign supervisors, different regimes can be found all over the world. ${ }^{57}$ There are only very few jurisdictions where cross-border information exchange is either completely free or fully restricted. In most jurisdictions, such information exchange is possible under certain criteria that, however, vary considerably. Those include the ability of the receiving supervisor to keep the information confidential, the use of the information for supervisory purposes only, the connection of the information to a company or branch in the other country or the relevance of the information for the receiving authority. In some cases, formal requirements for the information request exist.

In the EU, the single market in insurance gave need to an easy flow of information based on a common legal framework on professional secrecy. ${ }^{58}$ Since the confidentiality requirements are the same for all EU member states a rapid exchange of information can take place without any further requirements to check the legal situation.

Beyond the EU, it is neither a very realistic expectation nor in the competence of insurance supervisors to harmonise the underlying approaches in the different jurisdictions. Therefore, the most efficient way to deal with the issue in practice is to conclude the so-called Memoranda of Understanding, not only on a bilateral but also on a multilateral basis. Through those memoranda, the supervisors express their willingness to exchange information and cooperate within the existing legal framework.

\footnotetext{
${ }^{54}$ If cross-sector information exchange is concerned, for example, in the case of outsourcing of investment activities of an insurance undertaking to a bank in another jurisdiction.

${ }^{55}$ Braumüller (1996, p.19).

56 Ibid.

${ }^{57}$ Ibid. pp. 23-24 and IAIS Insurance Laws Database.

${ }^{58}$ EU Council of Ministers (1992, Art. 16; 2002a, Art. 16; 2005, Art. 24-30).
} 


\section{International standards and systems for information exchange and cooperation}

Already from the very beginning and before the IAIS became the international standard setter for insurance supervision in 1996, the issue of information exchange and cooperation between insurance supervisors globally was high on the IAIS agenda. The principle of information exchange and cooperation is part of the IAIS by-laws and thus a governing principle of the organisation.

At the first IAIS Annual Conference in 1994, an Exchange-of-Information Committee was established, which immediately started to work on the preparation of a recommendation on information exchange and cooperation between supervisors. Nearly one year later, the official signing of the IAIS Recommendation concerning Mutual Assistance, Cooperation and Sharing of Information took place. More than 50 IAIS members signed the recommendation thus agreeing to work - on a best efforts basis and within existing national legislation - towards increasing information exchange and strengthening mutual cooperation and assistance.

In 1997, a model Memorandum of Understanding was developed that served as the basis for bilateral MoUs between supervisors. The main objective of concluding an $\mathrm{MoU}$ between supervisors is to establish a formal basis for the information exchange and to facilitate cooperation in practice. An MoU expresses a strong commitment of supervisors to cooperate on the basis of existing legislation and within the existing regulatory framework. Therefore, it is crucial that the supervisory authorities concerned are well aware of the legal framework on information exchange and cooperation in the other jurisdiction because only then the cooperation will be effective and also work in the event of a company or market crisis.

At present, information exchange and supervisory cooperation form a crucial part of the IAIS Insurance Core Principles. There is one ICP explicitly dealing with supervisory cooperation and information exchange ${ }^{59}$ and - in addition - some other ICPs are referring to the need of information exchange and collaboration in specific areas. Furthermore, the IAIS Supervisory Standard No 6 on the Exchange of Information deals with those issues in more detail. ${ }^{60}$

According to ICP 5 , the supervisory authorities cooperate and share information with other relevant supervisors subject to confidentiality requirements. The confidentiality principle requires that information delivered by a supervisor remains confidential with the receiving supervisor. Furthermore, information received from another supervisor should only be used for supervisory purposes. The insurance supervisor should be able to enter into agreements or understandings with other supervisors without a formal agreement being a prerequisite for information sharing. No strict reciprocity should be applied in terms of level, format and detailed characteristics of the information exchanged.

Over recent years the internationalisation of the insurance business has speeded up, which makes information exchange arrangements between supervisors of internationally active large insurers, groups or conglomerates much more difficult. If the

\footnotetext{
${ }^{59}$ IAIS (2003, ICP 5, pp. 13-14).

${ }^{60}$ IAIS (2002).
} 
supervisors of an existing group or internationally active insurer have already based their cooperation on a network of bilateral MoUs and the respective insurer or group enters into a new market, the need for bilateral MoUs between the insurance supervisor in that new market and the supervisors in all the other markets where the insurer has already been doing business arises. In order to overcome these difficulties, and following an approach already taken by IOSCO several years ago, the IAIS is now in the process of developing a multilateral MoU, the so-called MMoU. Following up on what was said about the differences in legal provisions relevant to cross-border information exchange, the examination of the different national legal regimes will not be very easy but at the end the benefits of such a multilateral MoU will clearly prevail as the positive experience in the EU has shown.

In the EU, the information exchange and cooperation between insurance supervisors are based on the relevant provisions of the Directives. In order to facilitate the application of those rules in practice regular meetings of the European supervisors were introduced and the so-called cooperation protocols were developed. Already very soon after the signing of the Treaty of Rome establishing the EEC, the Conference of Insurance Supervisors of EEC Member States was founded. The Conference started to hold regular meetings and to discuss issues of the European insurance market. It became clear that a framework for multilateral cooperation was needed to allow a good functioning of the European insurance market. Although not directly based on any EU legislation, the Conference was recognised through Directive $91 / 675 /$ EEC on the establishment of the EC Insurance Committee. Today, the cooperation between EU insurance supervisors takes place in the framework of the Committee of European Insurance and Occupational Pensions Supervisors (CEIOPS), one of the so-called Level-3 Committees in the Lamfalussy structure.

In order to make the rules on supervisory cooperation in the Directives effective in their practical implementation, the Conference and later CEIOPS developed a set of multilateral cooperation protocols. The most important protocols for the insurance sector are the Helsinki Protocol on insurance groups supervision, the Luxemburg Protocol on intermediaries supervision and the Siena Protocol on general issues of cooperation based on the EU life and non-life Directives. At present, the Siena Protocol is being revised, taking into account changes in European legislation and practical experience in supervisory cooperation over the last 10 years and also focusing on issues of consumer protection and complaints handling.

\section{Conclusions}

Recent years have been characterised by increasing internationalisation of the insurance business. Cross-border activities by insurance companies and groups raise the need for cross-border cooperation between insurance supervisors in order to maintain the same level of supervision.

The ability to achieve the key objectives of insurance supervision, namely the protection of policyholders and the maintenance of insurance market stability, is increasingly depending on active and effective cooperation with supervisors in other jurisdictions. The risk profiles of internationally active insurance companies and groups are strongly influenced by the risks connected to their activities abroad. This 
does not only mean that risks already existing in the context of domestic business might grow but also that other risks might emerge.

International standards put high priority on information exchange and cooperation between insurance supervisors. In general, the information exchange and cooperation between supervisors has improved considerably over recent years. However, recent self-assessment exercises against the IAIS Insurance Core Principles have demonstrated that there is still room for further improvement as concerns observance of ICP 5 on supervisory cooperation and information sharing. And also in the EU, where cooperation plays a particularly important role because of the single insurance market, recent policy papers see the need to reinforce the supervisory authorities' obligations to cooperate to achieve greater supervisory cooperation and to improve cross-border supervision. ${ }^{61}$

Information exchange and cooperation between insurance supervisors should start as early as possible. This could for example be the licensing procedure, if the head office or parent company or another related entity is an insurance company or another regulated financial entity in a different jurisdiction.

Cases where the foreign business of an insurance company or group makes up a significant portion of the insurer's total business or where the business of an insurance company or group in a foreign market is systemically important for that market need particular attention by the supervisors involved and would normally require more intense cooperation.

Because of the increasing number of supervisors to be involved in the supervision of internationally active insurers and groups, it is necessary to develop instruments of multilateral cooperation to replace the existing bilateral arrangements to the extent possible.

The routine cases in which information should be exchanged should be agreed between supervisors and implemented as standard procedures in their internal guidelines. Beyond that, regular face-to-face meetings could significantly contribute to effective practical cooperation. However, what is really crucial is the exchange of information by supervisors on their own initiative, which has to supplement the routine procedures of information exchange. In cases where a supervisory authority is not able to ask for a certain information because it is not aware that this information is available only exchange of information initiated by the supervisor holding the information can produce satisfactory results. It seems that active information policy by supervisors can be further strengthened.

Although formal agreements or understandings should not be a prerequisite for supervisory cooperation on a cross-border basis, there should be sufficient clarity among the supervisors involved about their respective legal bases for information exchange and cooperation. Effective cooperation - in particular in urgent or crisis situations - cannot take place if long and difficult examinations have to be made before deciding on which information can be passed on to another supervisor or whether a joint on-site inspection can take place. On the other hand, the simple

${ }^{61}$ For example, COM (2005, 629final, point 3.2); FSC (2006, endorsed by Ecofin May 2006, paras 9 and 13). 
existence of agreements or understandings between supervisors is not sufficient. Information exchange and cooperation have to be tested in practice.

As a conclusion, effective supervision of insurance undertakings and in particular of internationally active insurers, insurance groups and financial conglomerates is only possible if appropriate and timely information exchange takes place between supervisors. ${ }^{62}$ This is equally necessary to reach both key objectives of insurance supervision, namely the protection of policyholders and the promotion of fair, safe and stable insurance markets. ${ }^{63}$

\section{References}

Braumüller, P. (1996) Exchange of Information - Legislation in IAIS Member Countries, Basel: IAIS. COM (2005) White Paper on Financial Services Policy 2005-2010, Brussels: COM.

EU Council of Ministers (1973) First Council Directive 73/239/EEC of 24 July 1973 on the coordination of laws, regulations and administrative provisions relating to the taking-up and pursuit of the business of direct insurance other than life assurance, Brussels: EU Council of Ministers, 24 July.

EU Council of Ministers (1988) Second Council Directive 88/357/EEC of 22 June 1988 on the coordination of laws, regulations and administrative provisions relating to direct insurance other than life assurance and laying down provisions to facilitate the effective exercise of freedom to provide services and amending Directive 73/239/EEC, Brussels: EU Council of Ministers, 22 June.

EU Council of Ministers (1992) Council Directive 92/49/EEC of 18 June 1992 on the coordination of laws, regulations and administrative provisions relating to direct insurance other than life assurance and amending Directives 73/239/EEC and 88/357/EEC (third non-life insurance Directive), Brussels: EU Council of Ministers, 18 June.

EU Council of Ministers (1998) Directive 98/78/EC of the European Parliament and of the Council of 27 October 1998 on the supplementary supervision of insurance undertakings in an insurance group, Brussels: EU Council of Ministers, 27 October.

EU Council of Ministers (2002a) Directive 2002/83/EC of the European Parliament and of the Council of 5 November 2002 concerning life assurance, Brussels: EU Council of Ministers.

EU Council of Ministers (2002b) Directive 2002/87/EC of the European Parliament and of the Council of 16 December 2002 on the supplementary supervision of credit institutions, insurance undertakings and investment firms in a financial conglomerate and amending Council Directives 73/239/EEC, 79/267/EEC, 92/49/EEC, 92/96/EEC, 93/6/EEC and 93/22/EEC, and Directives 98/78/EC and 2000/12/EC of the European Parliament and of the Council, Brussels: EU Council of Ministers, 16 December.

EU Council of Ministers (2005) Directive 2005/68/EC of the European Parliament and of the Council of 16 November 2005 on reinsurance and amending Council Directives 73/239/EEC, 92/49/EEC as well as Directives 98/78/EC and 2002/83/EC, Brussels: EU Council of Ministers, 16 November.

FSC (2006) Report on Financial Supervision, Francq Report, FSC 4159/06, February, endorsed by Ecofin May 2006, paras 9 and 13.

IAIS (2002) Supervisory Standard on the Exchange of Information, Basel: IAIS (January).

IAIS (2003) Insurance Core Principles and Methodology, Basel: IAIS (October).

IAIS (2004) Principles on Supervision of Insurance Activities on the Internet, Basel: IAIS (October).

\section{About the Author}

Peter Braumüller is Director of the Department of Insurance and Pension Company Supervision at the Financial Market Authority in Vienna, Austria.

\footnotetext{
${ }^{62}$ See IAIS (2003, ICP 5, Explanatory note, point 5.1).

${ }^{63}$ See Ibid, ICP 2, Essential criterion b.
} 